\title{
THE EFFECT OF PAPAIN ENZYME DOSAGE ON THE MODIFICATION OF EGG- YOLK LECITHIN EMULSIFIER PRODUCT THROUGH ENZYMATIC HYDROLYSIS REACTION
}

\author{
Setiadi $^{1 *}$, Nurul Hidayah ${ }^{1}$ \\ ${ }^{1}$ Department of Chemical Engineering, Faculty of Engineering, Universitas Indonesia, Kampus UI \\ Depok. Depok 16424, Indonesia
}

(Received: December 2017 / Revised: January 2018 / Accepted: February 2018)

\begin{abstract}
Lecithin is needed as a bioemulsifier product in stabilizing agents for the food, pharmaceutical and cosmetic industries due to its renewability and as it is environmentally friendly. In the food industry, most of the emulsifiers used are the oil-in-water $(\mathrm{O} / \mathrm{W})$ type. Lecithin can be seen as a promising emulsifier product because it is extracted from egg yolk and modified by enzymatic hydrolysis reaction using the papain enzyme. This modification will change the molecular structure of the compound, which makes lecithin more stable in the oil-in-water type of emulsion. This study aims to determine the optimum amount of papain enzyme used in the hydrolysis reaction to achieve the most stable $\mathrm{O} / \mathrm{W}$ lecithin emulsion type. The results show that the breaking of a single fatty acid chain from the structure of lecithin can be demonstrated by FTIR instrumentation. The fatty acids detected from the lecithin structure are shown at wavenumber $1699.45 \mathrm{~cm}^{-1}$ (C=O), $1231.44 \mathrm{~cm}^{-1}$ (C-O), $1422.45 \mathrm{~cm}^{-1}$ (C-O-H), $1092.85 \mathrm{~cm}^{-1}$ (C-C), 665.89 $\mathrm{cm}^{-1}\left(\mathrm{CH}_{2}\right)$, and 3400.57 (-OH in carboxylate). Determination of the modified lecithin yield was made by several tests, namely a stability test, and tests for acid value, surface tension and zeta potential. From the results of tests, the emulsion stability for the O/W type was achieved in modified-lecithin using a 4\% papain enzyme dosage, with a stability duration of up to 31 hours. The lowest acid number was achieved in modified-lecithin using a $2 \%$ papain enzyme dosage with value of 10.40 . The lowest surface tension was obtained in modified-lecithin using a $2 \%$ papain enzyme dosage with a surface tension value of 48.68 dyne $/ \mathrm{cm}$. The zeta potential of the modified-lecithin using a $2 \%$ papain enzyme had a value of $-94.8 \mathrm{mV}$. These results show that the enzymatic hydrolysis of lecithin using a papain enzyme is clearly able to enhance the emulsifier properties of the lecithin produced.
\end{abstract}

Keywords: Emulsifier; Enzymatic hydrolysis; Extraction; Lecithin; Papain enzyme

\section{INTRODUCTION}

Currently, most surfactants or emulsifiers are manufactured from either petrochemicals or seed oils, such as palm or coconut oil. Petrochemical-based emulsifiers introduce carbon dioxide into the atmosphere as they degrade. Expansion of palm and coconut oil production can also introduce carbon dioxide into the atmosphere rainforests are destroyed (Biotechnology Industry Organization, 2011). Tightening environmental regulations and increasing awareness intend to protect the ecosystem and have effectively resulted in increasing interest in biosurfactants as possible alternatives to chemical surfactants. Biosurfactants are amphipathic surface-active compounds produced by different living organisms that can form and stabilize oil-water or water-

\footnotetext{
*Corresponding author's email: setiadi@che.ui.ac.id, Tel: +62-21-7863516, Fax: +62-21-7863515 Permalink/DOI: https://dx.doi.org/10.14716/ijtech.v9i2.1073
} 
-oil emulsions (Banat et al., 2000; Dastghieb et al., 2008). Biosurfactants, usually referred to as bioemulsifiers, have the same function as synthetic surface active agents from renewable ingredients rather than crude

oil or natural gas hydrocarbons. Initial interest in bioemulsifier compounds was due to their ability to increase the solubility of insoluble or poorly soluble hydrocarbons (Lopes et al., 2014). However, the increasing environmental concern about chemical surfactants has focused attention on microbial-derived surface-active compounds, essentially due to their low toxicity and biodegradable nature (Nitschke \& Costa, 2007). The capability of lecithin as a bioemulsifier means it has been widely used as an emulsifier in food, pharmaceutical and cosmetic manufacturing (Schneider, 2001), as it is a renewable product that can replace more energyintensive and expensive petrochemical-derived chemicals and materials.

Recently, the need for lecithin in Indonesia has been fulfilled by importing it from lecithinproducing countries such as Japan, America and the Netherlands. Reckziegel (2014) defines lecithin as a complex mixture of acetone-insoluble phosphatides consisting of phosphatidylcholine (PC), phosphatidylethanolamine (PE) and phosphatidylinositol (PI), combined with other substances such as triglycerides, fatty acids and other minor compounds. Interest in the investigation of egg-yolk lecithin isolation has increased due to its high lecithin content. Phosphatidylcholine from egg yolk is reported to have low cholesterol values compared to soybean phosphatidylcholine (Jiang et al., 2001). In addition, lecithin from egg yolk has better oxidative stability than soy lecithin, and phospholipids from the egg yolk also exhibit antioxidant properties (Nimalaratne \& Wu, 2015).

The modification of lecithin aims to change the solubility characteristics of lecithin compounds. Lecithin is a more lipophilic emulsifier, which has a tendency to form a water-in-oil emulsion type (W/O). The modifications are essential for achieving and adjusting optimal ratios between hydrophilic and lipophilic properties and for ensuring it is a good food processing ingredient (Nieuwenhuyzen \& Tomás, 2008). This process makes lecithin have the tendency to form an oilin-water emulsion type $(\mathrm{O} / \mathrm{W})$. Elimination of one molecule fatty acid from the sn-1 position is expected to increase the hydrophilic lipophilic balance and enhance the capability to stabilize the oil-in-water emulsion (Estiasih et al., 2013). The reaction between lecithin and papain enzyme is shown in Figure 1.

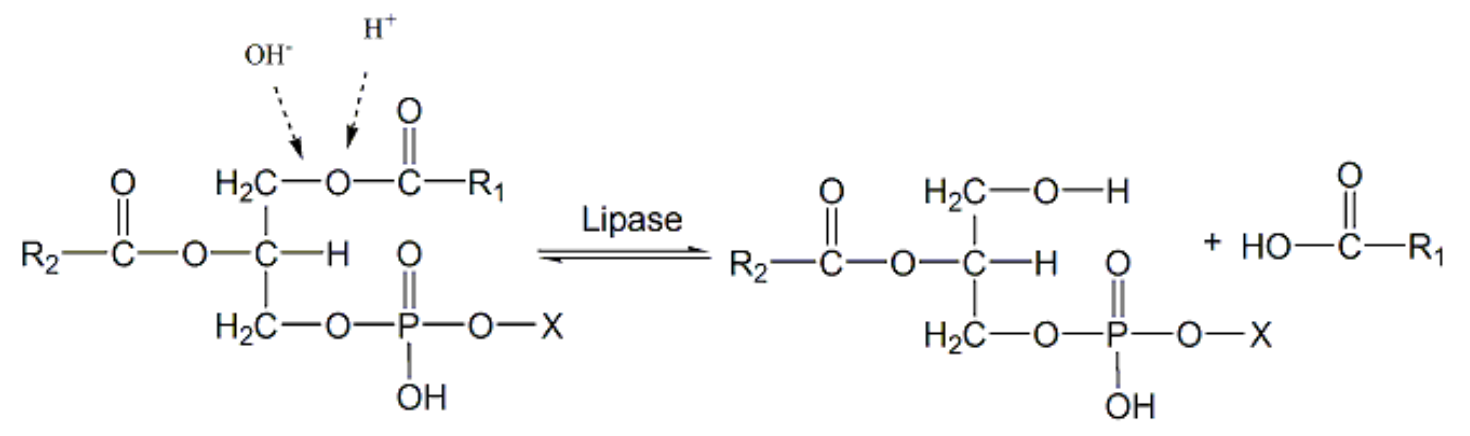

Figure 1 Hydrolysis reaction of lecithin with lipase enzyme in aqueous conditions

From Figure 1, it can be seen that the structure of lecithin has two fatty acid chains at the position of $\operatorname{Sn} 1\left(\mathrm{R}_{1}\right)$ and $\operatorname{Sn} 2\left(\mathrm{R}_{2}\right)$ of the lipophilic group. Under natural conditions, the lipase catalyzes the hydrolysis of ester bonds at the interface between an insoluble substrate phase and the aqueous phase, where the enzyme remains dissolved (Sharma \& Kanwar, 2014). In this conditions, hydroxyl $\left(\mathrm{OH}^{-}\right)$from water molecules would bind the fatty acid at the sn-1 position and produce free fatty acid. Once lecithin loses its fatty acid, the carbon atoms at the sn- 1 position would bind 
with $\mathrm{H}^{+}$to form lysolecithin. Meanwhile, in non-aqueous conditions they catalyze the reverse reaction, producing glycerides from glycerol and fatty acids.

The use of enzymes for the optimization of lecithin characteristics has several advantages, such as high selectivity, and the ability to yield products that cannot be made by other methods (Reckziegel, 2014). Enzymatic modification has attracted increasing interest, as enzymes can be used to modify phospholipids in a wide variety of ways (Vikbjerg et al., 2006). Enzymatic modification is aimed at obtaining more hydrophilic lecithin (Joshi et al., 2006) with better oilin-water emulsifying properties (Nieuwenhuyzen \& Tomas, 2008). In addition, this modification may have technological and commercial advantages over lecithin in enhancing $\mathrm{O} / \mathrm{W}$ emulsifying properties (Cabezas et al., 2012).

Several studies have been conducted to modify lecithin, made by using expensive commercial phospholipase. This study was conducted using papain enzyme from Carica papaya latex (CPL). The presence of lipase activity was first reported by Giordani et al. (1991), who showed it could be used advantageously for oil and fat modification. Carica papaya latex can be a useful biocatalyst for the synthesis of triacylglycerols (TAGs) structures with improved chemical or physical properties (Asomaning \& Curtis, 2017). The papain enzyme is a hydrolase enzyme that catalyzes the hydrolysis reaction of a substrate with the help of water molecules. In addition, the enzyme is easy to obtain and the price is more affordable than phospholipase A2 and A1. This study aims to determine the optimum amount of papain enzyme used in the hydrolysis reaction of lecithin in order to obtain better emulsifier properties of lecithin in the O/W type emulsion.

\section{METHODS}

\subsection{Egg-yolk Lecithin Extraction}

The lecithin extraction was carried out according to Palacios and Wang (2005), with some modification. It was extracted from egg yolk by absolute ethanol extraction. All the solvents were Merck based chemicals purchased from Bratachem. About $20 \mathrm{~g}$ of egg yolk obtained from local eggs was placed into a glass beaker, with the addition of approximately $100 \mathrm{ml}$ of analytical grade ethanol, to give a final 1:5 ratio of egg yolk (wet weight) to ethanol. The mixture was stirred until the egg yolks were completely dispersed. The sample was then centrifuged (Changsha Weiekang Xiangying Centrifuge, TDZ5-WS) at $1000 \mathrm{RCF}$ for $5 \mathrm{~min}$. The phospholipid (PL) fraction (supernatant) had been previously transferred to a weighted round-bottomed flask and the ethanol then was removed by rotary evaporation IKA RV 10. To ensure that the ethanol was totally removed, the $\mathrm{PL}$ fraction residue was obtained by drying in an oven at $60^{\circ} \mathrm{C}$ (Biobase Bioindustry Co.Ltd Model BOV-T30C) until the sample was in paste form. This crude lecithin was weighed and characterized by FT-IR (Thermo Scientific, Nicolet iS5).

The crude lecithin was then purified to reduce the possibility of it containing oil; this process refers to the method used by Nasir et al. (2007), with some modified methods. Absolute acetone was added to the dried crude lecithin in the ratio of crude lecithin to acetone of 1:6 (w/v) and the mixture was stirred. The solvent and lecithin were separated by filter paper (Whatman), and the treatment was repeated until the solvent was colorless.

\subsection{Lecithin Modification}

For the enzymatic hydrolysis process, the lipase enzyme used was a papain enzyme obtained from crude papaya latex extract (Carica papain latex). This modification method follows the research conducted by Estiasih et al. (2013), but differs in the type of enzyme and variation used. About $5 \mathrm{~g}$ of purified lecithin was added to $25 \mathrm{ml}$ of water (20\% v/v solvent) and mixed. Dosages of 2, 4, 6, 8 and 10\% papain enzymes from the weight of lecithin used were prepared. Absolute diethyl ether was then added to each papain enzyme dosage (10\% w/v solvent) and stirred, and subsquently poured into the lecithin mixture. This mixture was incubated for 30 minutes at $37^{\circ} \mathrm{C}$, 
and the solvent was then filtered and purified using acetone $96 \%$ with ratio of 1:4 to remove the free fatty acids contained in the mixture. The solvent was then measured by a Fourier Transmission Infrared (FT-IR) instrument to confirm that the hydrolysis reaction using the papain enzyme had been successful in breaking down the fatty acids from the lecithin molecule structure.

\subsection{Data Analysis}

The determination of the modified lecithin was performed by several tests, such as a stability test, and test for surface tension and zeta potential. The performance of the modified lecithin was analyzed by its ability as an emulsifier on mixing water and oil by determining how long the lecithin could stabilize the dissolution of immiscible compounds. The acid value was determinated by (SNI) 01-3555-1998. The measurement of the surface tension of the lecithin refers to Lamour et al. (2010), which was determined based on size drop analysis. The surface tension was calculated by a Zisman plot, and measurement of the zeta potential was made using a Horiba Nano Partica SZ-100 instrument.

\section{RESULTS AND DISCUSSION}

\subsection{Extracted Lecithin}

The results of the lecithin extracted from egg yolk were determined using analytical balance; the crude lecithin content of egg yolk resulted in a yield of $9.7 \%$, while purification by acetone washing produced a purified lecithin yield of $8.24 \%$ from the total egg yolk weight. According to Vikbjerg et al. (2006), crude lecithin contains impurities such as triglycerides and other nonpolar lipids. The triglycerides were dissolved in acetone; repeated acetone washing led to the removal of the triglycerides, and increasing lecithin purity (Estiasih et al., 2013). With acetone extraction, phospholipids become more concentrated, which results in significantly lower dosage requirements and higher functionalities.

The results of this experiment showed a relatively lower yield compared to that obtained by $\mathrm{Al}$ Abayaji (2015), with a lecithin yield of $10.29 \%$, and the research of Palacios and Wang (2005), with a yield of $13.5 \%$. In Palacios and Wang study, the lecithin was extracted from the egg yolk through multiple extraction, i.e. extraction of phosphatidylcholine, a deoiling process and finally extraction of the remaining phospholipids. The second and third steps were not performed in this study. Because the remaining phospholipids from the residues of the initial extract were in relatively small amounts, a gradual extraction process which requires additional time and cost for other solvents was required. This research was therefore only carried out for lecithin in one phosphatidylcholine extraction stage. However, the results were not very different from previous research; the data obtained here suggest that further extraction is unnecessary for phospholipid extraction, and that ethanol is possibly a strong polar solvent that can disrupt protein-lipid interaction in the yolk lipoproteins.

\subsection{Modified Lecithin}

From the results of the research, enzyme hydrolysis reactions are shown to be able to change the appearance of phospholipids in extracted lecithin, as demonstrated by the change of color of the lecithin to golden yellow. This could be seen from the appearance of the free fatty acids on the lecithin, which had reacted with the papain enzyme, even during a reaction time of just 10 minutes.

The dissolution of the papaya latex into diethyl ether serves as papain enzyme dispersion for easy spread to the lecithin solution. Diethyl ether was chosen as the solvent in this hydrolysis reaction because it is an organic compound with a low boiling point. Using the lipase enzyme, no reaction was observed without the addition of lecithin to the organic solvent. In other words, organic solvents are an appropriate choice as a medium for lipase enzyme removal, because this particular solvent did not react with the lipase enzyme. In addition, due to its high volatility, diethyl ether 
can evaporate at temperatures above $35^{\circ} \mathrm{C}$ in reaction times of 10 minutes. The mixture was then incubated at $37^{\circ} \mathrm{C}$.
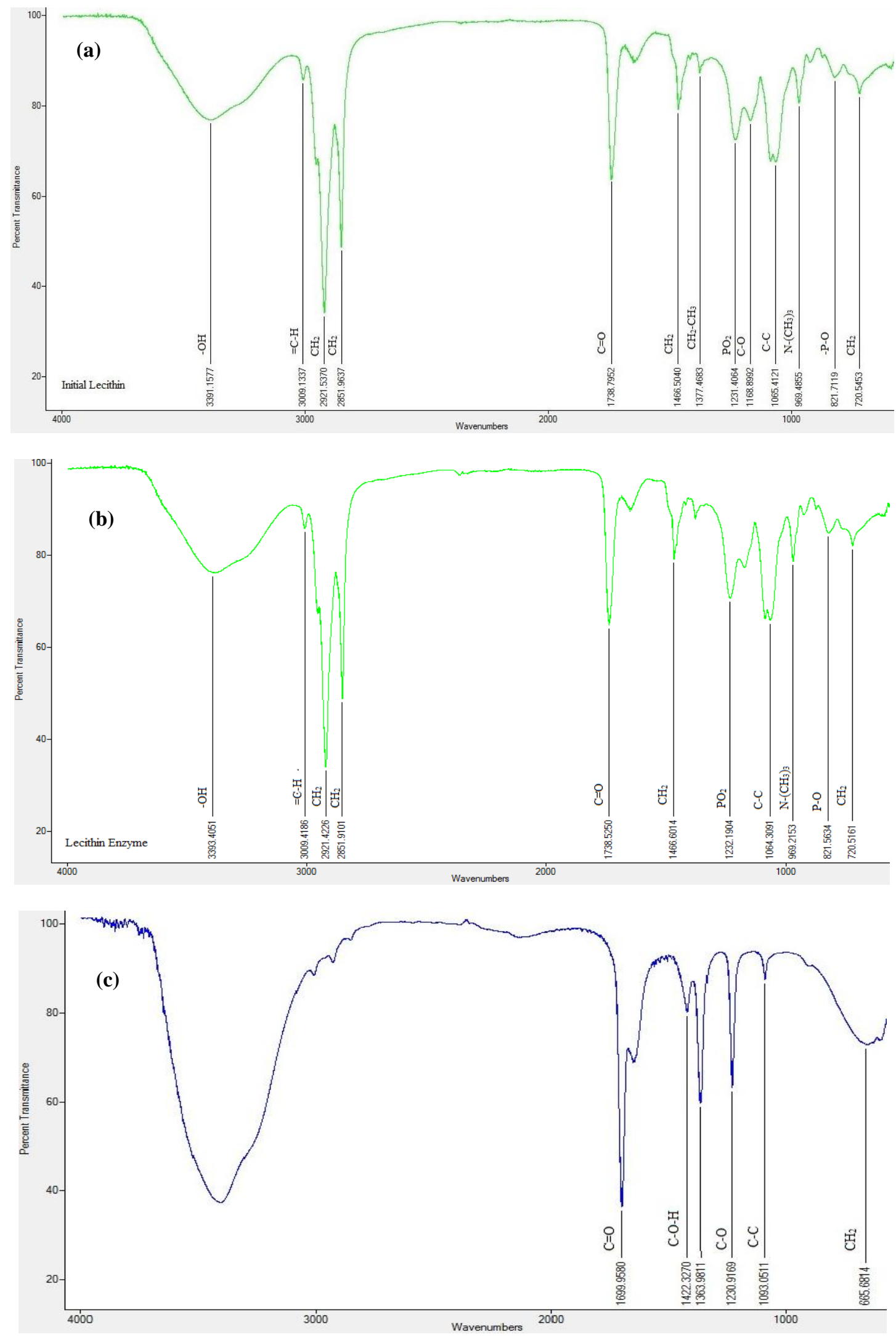

Figure 2 FT-IR spectrum of: (a) purified lecithin; (b) modified lecithin; and (c) breaking down of single fatty acid 
To improve the handling of the highly viscous crude lecithin and to improve disperability, industry commonly uses acetone deoiling (Vikbjerg, 2006). Acetone disolved with fatty acids and modified lecithins were obtained as precipitated by filtration. To remove the acetone and water remaining in the modified lecithin, the lecithin was dried in an oven. To compare the components of the extracted lecithin with the modified lecithin, the following test was analyzed using a Fourier transform infrared spectrophotometer (FT-IR Thermo Scientific, Nicolet iS5). The results of the FT-IR spectrum are shown in Figure 2. It is clear that the IR spectra of bonds (in units of wavenumbers) were contained in the purified and modified lecithin.

Based on Figure 2, it can be seen that both the purified and modified lecithin had a slightly different IR spectrum. From the test results with this FTIR, it can be seen that the extracted lecithin had a $\mathrm{N}\left(\mathrm{CH}_{3}\right)_{3}$ group bond at $969 \mathrm{~cm}^{-1}, \mathrm{P}-\mathrm{O}$ at $821 \mathrm{~cm}^{-1}$ and $\mathrm{P}=\mathrm{O}$ at $1231-1232 \mathrm{~cm}^{-1}$. These bonds indicate that the bond structure of modified lecithin had the same typical standard bonds as the bond on the lecithin type phosphatidylcholine. Phosphatidylcholine is a phospholipid that binds the $\mathrm{N}\left(\mathrm{CH}_{3}\right)_{3}$ group in the $\mathrm{O}$ atom to its phosphate group.

The results show that the breaking of a single fatty acid chain from the structure of lecithin can be demonstrated by FTIR instrumentation (Figure 2c). Fatty acids that had been broken down from the lecithin structure were shown at wave number $1699.96 \mathrm{~cm}^{-1}$ showing the $\mathrm{C}=\mathrm{O}$ bond, $1230.92 \mathrm{~cm}^{-1}$ indicating the presence of a C-O bond, $1422.33 \mathrm{~cm}^{-1}$ indicating the presence of a C-O-H bond, $1093.05 \mathrm{~cm}^{-1}$ with very low intensity showing the existence of a C-C bond, and $665.68 \mathrm{~cm}^{-1}$ wavenumber with widening peak showing the existence of a $\mathrm{C}-\mathrm{H}_{2}$ bond. The existence of these peaks shows that the acetone used in the dissolution of modified lecithin clearly contains a fatty compound. It can be concluded that the FTIR test results for this acetone dissolution show that the papain enzyme taken directly from papaya latex had catalyzed in the fatty acid chain by hydrolyzing the reaction of the $\mathrm{C}$ glycerol chain.

\subsection{Stability of Modified Lecithin}

Based on the results of the research, the stability of the emulsion for the 1:5 oil water ratio with the addition of hydrolysed lecithin at varying papain enzyme dosages is shown in Figure 3.

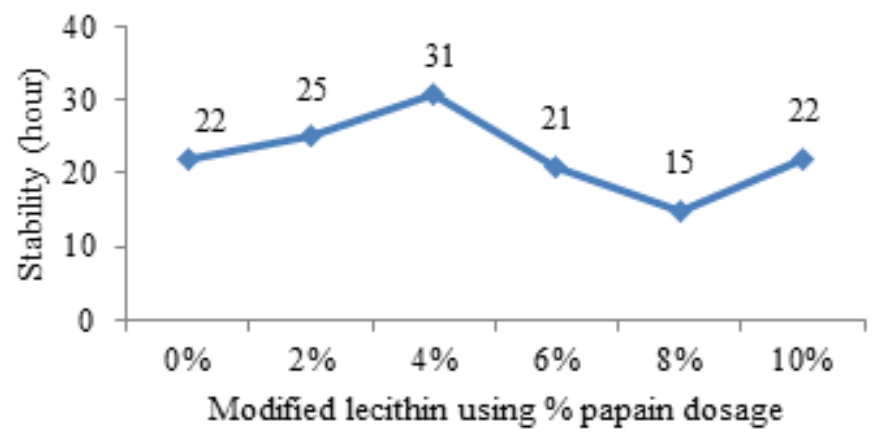

Figure 3 Stability of oil and water emulsion with addition of modified lecithin

Modified lecithin with $2 \%$ and $4 \%$ papain dosages had a relatively high stability of the oil-water emulsion. Both had a stable tendency to form an $\mathrm{O} / \mathrm{W}$ emulsion, but the highest stability profile was indicated by the $4 \%$ lecithin sample. It can be seen that the hydrolysis of lecithin using $2 \%$ and $4 \%$ papain enzyme dosages was able to cut most of the fatty acid group. The more the fatty acid could be cut by the enzyme, the more hydrophilic the lecithin.

The crude lecithin had an HLB value of 5.0, suitable for water-in-oil (W/O) emulsions. Many food emulsion systems are oil-in-water $(\mathrm{O} / \mathrm{W})$ emulsions, such as milk, mayonnaise and coconut milk. Partial hydrolysis was expected to make lecithin more hydrophilic. In this study, the 
modified lecithin met its objective to make lecithin more hydrophilic, and it is shown that the $2 \%$ and $4 \%$ sample lecithin dosages had good stability in the oil-water emulsion.

Song et al. (2005) show that the water and enzyme concentration determines whether hydrolysis or esterification action of the enzyme is used. The use of a papain enzyme for a dosage higher than $4 \%$ decreased the stability of the lecithin; the decline in the hydrolysis reaction was due to lack of water content. Water was probably still available for use with the $4 \%$ papain enzyme, and a re-esterification reaction began to occur after the dosage was exceeded. Estiasih et al. (2013) mentioned that it was conclude that re-esterification of liberated free fatty acids into a lysophospholipid molecular structure is inhibited by the availability of water.

\subsection{Acid Value of Lecithin}

The acid number shows the amount of free fatty acid content found in the lecithin. The higher the value of the acid number, the lower the quality of the lecithin. The higher acid numbers show a greater number of fatty acid groups still bound to the carbon atom of the glycerol chain. Lecithin reaching the optimum condition for the $\mathrm{O} / \mathrm{W}$ emulsion could be obtained by observing the lowest acid value. The acid values of modified lecithin are shown in Table 1.

Table 1 Acid value of modified lecithin

\begin{tabular}{ccc}
\hline Sample & KOH Volume $(\mathrm{ml})$ & Acid value \\
\hline $0 \%$ & 1.70 & 13.60 \\
$2 \%$ & 1.30 & 10.40 \\
$4 \%$ & 1.40 & 11.20 \\
$6 \%$ & 1.50 & 12.00 \\
$8 \%$ & 1.60 & 12.80 \\
$10 \%$ & 1.80 & 14.40 \\
\hline
\end{tabular}

Based on Table 1, it shown that the lecithin had acid values ranging from 10.40 to 14.40 . The lowest value was shown in the modified lecithin with a $2 \%$ papain enzyme dosage, and this continues to increase with increasing doses of papain enzyme. Based on the results of the acid number test, it can be seen that the optimum condition for the lecithin hydrolysis reaction was achieved when the dosage of papain enzyme was $2 \%$. This indicates that the use of a $2 \%$ papain enzyme would cut most of the single fatty acid chain from the carbon atom of glycerol that made the less fatty acid content in lecithin. The breaking of one fatty acid chain from the lecithin molecular structure resulted in lecithin with decreased lipophilic properties, which led to a more water soluble lecithin. The lowest acid number was found using modified lecithin with a $2 \%$ papain enzyme dosage, with the value of 10.40, and the highest acid number was obtained using lecithin modified by $10 \%$ papain enzyme dosage, which attained the value of 14.40 . These results meet the standards of the American Lecithin Company, which states that the acid value should not exceed 36.

\subsection{Surface Tension of Modified Lecithin}

The two parameters of initial lecithin surface activity for the emulsifier function are the ability to lower water surface tension and to form a stable fatty acid in an oil-water $(\mathrm{O} / \mathrm{W})$ emulsion system. The surface tension parameters were measured with surface tension. The effect of papain enzyme dosage on the surface tension of lecithin is shown in Table 2. 
Table 2 Surface tension of modified lecithin

\begin{tabular}{ccc}
\hline Sample & Contact angle $\left({ }^{\circ}\right)$ & Surface tension $($ dyne $/ \mathrm{cm})$ \\
\hline $0 \%$ & 81.25 & 57.799 \\
$2 \%$ & 57.78 & 48.684 \\
$4 \%$ & 66.26 & 51.794 \\
$6 \%$ & 69.21 & 52.943 \\
$8 \%$ & 65.45 & 51.507 \\
$10 \%$ & 82.98 & 58.517 \\
\hline
\end{tabular}

In Table 2, it can be seen that hydrolysis reaction of lecithin using the papain enzyme could reduce the surface tension to $48.684 \mathrm{dyne} / \mathrm{cm}$. The tension decreases in modified lecithin with a $2 \%$ papain enzyme dosage and then increases up to the end of the data used, in lecithin with a $10 \%$ papain enzyme dosage. The lowest surface tension value was achieved by lecithin with the addition of $2 \%$ papain enzyme, with a value of $48.684 \mathrm{dyne} / \mathrm{cm}$. The breaking of one of the fatty acid chains in the lecithin structure resulted in an increase in the amphiphilic properties of the lecithin, thus allowing it to spread more easily.

The surface tension value of the modified lecithin using the papain enzyme was relatively similar to the modified lecithin using phospholipase enzymes. According to Shah et al. (2017), enzymatic partial hydrolysis of phospholipids obtained from the heads of autumn chum salmon using phospholipase A1 (PLA1) succeeded in reducing surface tension values to $30.5 \mathrm{dyne} / \mathrm{cm}$.

\subsection{Zeta Potential of Modified Lecithin}

Measurement of the zeta potential values was made only on the purified and modified lecithin using the $2 \%$ papain enzyme (modified lecithin with the best characteristics). The purified lecithin had a potential of $-37.5 \mathrm{mV}$, while that of the modified lecithin was $-94.8 \mathrm{mV}$. The particles with zeta potential above $+/-30 \mathrm{mV}$ showed stability, because the surface charge prevented particle aggregation. A higher zeta potential value will prevent coagulation (colloidal event) or make higher emulsion stability. Reducing the zeta potential value toward the isoelectric point (zero potential) allows the particles drop to attract each other and leads to a tendency to agglomerate. It can be seen that the hydrolysis of lecithin using the papain enzyme could increase the stability of lecithin in colloids.

\section{CONCLUSION}

The papain enzyme from crude papaya latex is an effective enzyme for lecithin modification in order to improve its availability and affordability. In addition, the reaction of enzymatic hydrolysis on egg yolk lecithin can be confirmed based on the FTIR spectrum. The purified egg yolk lecithin resulted in a yield of $8.24 \%$. The optimum amount of papain enzyme dosage to establish the best characteristic of modified lecithin was $2 \%$, based on the weight of egg yolk lecithin. The hydrolysis reaction of egg yolk lecithin using the papain enzyme increased the stability of lecithin in an $\mathrm{O} / \mathrm{W}$ emulsion to up to 31 hours, with a zeta potential value of -94.8 $\mathrm{mV}$. It also decreased the surface tension of lecithin to $48.68 \mathrm{dyne} / \mathrm{cm}$ as more polar lecithin was produced after the hydrolysis reaction. The acid value of modified lecithin decreased to 10.40 due to the decreasing fatty acid content. In further research, it is advised to use a larger amount of water during the lecithin modification process. 


\section{ACKNOWLEDGEMENT}

The authors would like to acknowledge the grant "Publikasi Internasional Terindeks untuk Tugas Akhir Mahasiswa" (PITTA) Universitas Indonesia with Grant number 832/UN2.R3.1/HKP.05.00/ 2017 in the year 2017, for its financial support during the research.

\section{REFERENCES}

Al-Abayaji, M. A., 2015. Extraction and Determination of Iraqi Boiled Egg Yolk Constituents, and Characterization of Lecithin. Department of Chemistry, Ibn Al Haitham College of Education.

Asomaning, J., Curtis, J.M., 2017. Enzymatic Modification of Egg Lecithin to Improve Properties, Food Chemistry, Volume 220, pp. 385-392

Banat, I.M., Makkar, R.S., Cameotra, S.S., 2000. Potential Commercial Applications of Microbial Surfactants. Applied Microbiology and Biotechnology, Volume 53(5), pp. 495508.

Biotechnology Industry Organization, 2011. Biotechnology Solutions for Renewable Specialty Chemicals \& Food Ingredients. Washington, DC: Biotechnology Industry Organization.

Cabezas, D., Madoery, R.M., Tomás, B.D.M.C., 2012. Emulsifying Properties of Different Modified Sunflower Lecithins. Journal of the American Oil Chemists' Society, Volume 89(2), pp. 335-361

Dastghieb, S.M.M., Amoozegar, M.A., Elahi, E., Asad, S., Banat, I.M., 2008. Bioemulsifier Production by a Halothermophilic Bacillus Strain with Potential Applications in Microbially Enhanced Oil Recovery. Biotechnol Lett, Volume 30(2), pp. 263-270

Estiasih, T., Kgs, A., Ginting, E., Priyanto, A.D., 2013. Modification of Soy Crude Lecithin by Partial Enzymatic Hydrolysis using Phosholipase A1. International Food Research Journal, Volume 20(2), pp. 843-849

Giordani, R., Moulin, A., Verger, R., 1991. Tributyroylglycerol Hydrolase Activity in Carica Papaya and Other Lattices. Phytochemistry, Volume 30(4), pp. 1069-1072

Jiang, Y., Noh, S.K., Koo, S., 2001. Egg Phosphatidylcholine Decreases the Lymphatic Absorption of Cholesterol in Rats. The Journal of Nutrition, Volume 131(9), pp. 2358-2363

Joshi, A., Paratkar, S.G., Thorat, B., 2006. Modification of Lecithin by Physical, Chemical and Enzymatic Methods. European Journal of Lipid Science and Technology, Volume 108(4), pp. 363-373

Lamour, G., Hamraoui, A., Buvailo, A., Xing, Y., Keuleyan, S., Prakash, V., Bafrooei, A.E., Borguet E., 2010. Contact Angle Measurements using a Simplified Experimental Setup. Journal of Chemical Education, Volume 87(12), pp. 1403-1407

Lopes, E.M., Castellane, T.C.L., Moretto, C., Lemos, E.G.D.M., Souza, J.A.M.D., 2014. Emulsification Properties of Bioemulsifiers Produced by Wild-type and Mutant Bradyrhizobium elkanii Strains. Journal of Bioremediation \& Biodegradation, Volume 5(6), pp. 1-6

Nasir, M.I., Bernards, M.A., Charpentier, P.A., 2007. Acetylation of Soybean Lecithin and Identification of Components for Solubility in Supercritical Carbon Dioxide. Journal of Agricultural and Food Chemistry, Volume 55(5), pp. 1961-1969

Nieuwenhuyzen, W.V., Tomas, M.C., 2008. Update on Vegetable Lecithin and Phospoholipid Technologies. European Journal of Lipid Science and Technology, Volume 110(5), pp. 472 486

Nimalaratne, C., Wu, J., 2015. Hen Egg as an Antioxidant Food Commodity: A Review. Nutrients, Volume 7(10), pp. 8274-8293

Nitschke, M., Costa, Siddhartha G.V.A.O., 2007. Biosurfactants in Food Industry. Trends in Food Science \& Technology, Volume 18(5), pp. 252-259 
Palacios, L.E., Wang, T., 2005. Egg Yolk Lecithin Fractionation and Characterization. J.American Oil Chemists' Society, Volume 82(8), pp. 571-578

Reckziegel, Y., 2014. Characterization and Comparison of the Functionality of Fractionated Lecithin from Different Sources. Master Thesis of Science in Food Technology. Faculty of Bioscience Engineering, Universiteit Gent.

Schneider, M., 2001. Phospholipids for Functional Food. European Journal of Lipid Science and Technology, Volume 103(2), pp. 98-101

Shah, A.K.M.A., Nagao, T., Kurihara, H., Takahashi, K., 2017. Production of a Health-beneficial Food Emulsifier by Enzymatic Partial Hydrolysis of Phospholipids Obtained from the Head of Autumn Chum Salmon. Journal of Oleo Science, Volume 66(2), pp. 147-155

Sharma, S., Kanwar, S.S., 2014. Organic Solvent Tolerant Lipases and Applications. The Scientific World Journal. Volume 2014, pp. 1-15

Song, J.K., Han, J.J., Rhee, J.S., 2005. Phospholipases: Occurrence and Production in Microorganisms, Assay for High-throughput Screening, and Gene Discovery from Natural and Man-made Diversity. Journal of the American Oil Chemists' Society, Volume 82(10), pp. 691-705

Vikbjerg, A.F., 2006. Enzyme Catalyzed Production of Phospholipids with Modified Fatty Acid Profile, Denmark: BioCentrum-DTU Technical University of Denmark

Vikbjerg, A.F, Rusig, J.Y., Jonsson, G., Mu, H., Xu, X., 2006. Comparative Evaluation of the Emulsifying Properties of Phosphatidylcholine after Enzymatic Acyl Modification. J. Agric. Food Chem, Volume 54(9), pp. 3310-3316 